\title{
Appraising the historical and projected spatiotemporal changes in the heat index in Bangladesh
}

\author{
Mahzabin Binte Rahman ${ }^{1} \cdot$ Roquia Salam ${ }^{1} \cdot$ Abu Reza Md. Towfiqul Islam ${ }^{1}\left(\right.$ D $\cdot$ Anjum Tasnuva $^{2} \cdot$ Ubydul Haque $^{3}$. \\ Shamsuddin Shahid ${ }^{4}$. Zhenghua Hu ${ }^{5}$. Javed Mallick ${ }^{6}$
}

Received: 19 March 2021 / Accepted: 19 June 2021 / Published online: 23 July 2021

(C) The Author(s), under exclusive licence to Springer-Verlag GmbH Austria, part of Springer Nature 2021

\begin{abstract}
Climate change-derived extreme heat phenomena are one of the major concerns across the globe, including Bangladesh. The appraisal of historical spatiotemporal changes and possible future changes in heat index (HI) is essential for developing heat stress mitigation strategies. However, the climate-health nexus studies in Bangladesh are very limited. This study was intended to appraise the historical and projected changes in $\mathrm{HI}$ in Bangladesh. The $\mathrm{HI}$ was computed from daily dry bulb temperature and relative humidity. The modified Mann-Kendal (MMK) test and linear regression were used to detect trends in $\mathrm{HI}$ for the observed period (1985-2015). The future change in HI was projected for the mid-century (2041-2070) for three Representative Concentration Pathway (RCP) scenarios, RCP 2.6, 4.5, and 8.5 using the Canadian Earth System Model Second Generation (CanESM2). The results revealed a monotonic rise in the HI and extreme caution conditions, especially in the humid summer season for most parts of Bangladesh for the observed period (1985-2015). Future projections revealed a continuous rise in $\mathrm{HI}$ in the forthcoming period (2041-2070). A higher and remarkable increase in the HI was projected in the northern, northeastern, and south-central regions. Among the three scenarios, the RCP 8.5 showed a higher projection of HI both in hot and humid summer compared to the other scenarios. Therefore, Bangladesh should take region-specific adaptation strategies to mitigate the impacts of HI.
\end{abstract}

Keywords Heat index $\cdot$ Heat stress $\cdot$ Spatiotemporal change $\cdot$ Statistical downscaling $\cdot$ CanESM2

Abu Reza Md. Towfiqul Islam

towfiq_dm@brur.ac.bd

$\triangle$ Javed Mallick

jmallick@kku.edu.sa

1 Department of Disaster Management, Begum Rokeya University, Rangpur 5400, Bangladesh

2 Institute of Disaster Management, Khulna University of Engineering \& Technology, Khulna 9208, Bangladesh

3 Department of Biostatistics and Epidemiology, University of North Texas Health Science Center, Fort Worth, TX, USA

4 Department of Water \& Environmental Engineering, School of Civil Engineering, Universiti Teknologi Malaysia (UTM), 81310 Johor Bahru, Johor, Malaysia

5 School of Applied Meteorology, Nanjing University of Information Science \& Technology, Nanjing 210044, China

6 Department of Civil Engineering, College of Engineering, King Khalid University, PO Box 394, Abha 61411, Saudi Arabia

\section{Introduction}

Climate change-derived heat extremes have become a matter of global concern with the rapid rise in temperature (Rajib et al. 2011; Rakib 2013; Ballester et al. 2016; Nissan et al. 2017; Rahman et al. 2019). The climate influences public health mainly through temperature extremes. Though cold extremes are more deadly than heat extremes (Dixon et al. 2005), a gradual rise in earth temperature due to climate change has made heat extremes the primary concern to public health throughout the globe (Field et al. 2014). According to the United Nations Office for Disaster Risk Reduction (UNISDR, 2018), nearly 166,000 people died between 1998 and 2017 due to heat extremes. Global Change (2018) report estimated about 9300 deaths per year by 2090 due to temperature extremes. The rising temperature would cause a gradual decrease in cold extreme-related fatalities and an increase in heat extreme-related health consequences. Therefore, the majority of public health implications in the future would be due to heat extremes. Many studies have been conducted to assess 
extreme heat effects on different human health aspects in recent decades, considering their severe consequences (Monteiro et al. 2013; McGregor et al. 2015; Ballester et al. 2016; Pal and Eltahir 2016; Modarres et al. 2018).

Temperature-based indices are generally used to appraise human exposure to extreme heat. Heat exposure is defined as a negative function of temperature, relative humidity, solar radiation, and wind speed that human experiences (Blazejczyk et al. 2012; Nguyen and Dockery 2016). In contrast, the heat index (HI) is commonly known as the apparent temperature experienced by the human body. Therefore, the $\mathrm{HI}$ is generally used to measure human exposure to extreme heat. However, the measures of the HI vary according to the local climate and vulnerability of the population. Therefore, many HIs have been developed to assess human exposure to extreme heat (De Freitas and Grigorieva 2014). According to Modarres et al. (2018), out of 170 climate indices available to evaluate various climatic conditions, over 100 indices are designed to assess the nexus between meteorological parameters and $\mathrm{HI}$.

The human capability to adapt to heat is directly related to dry bulb temperature and humidity (Raymond et al. 2017). Therefore, the HI based on temperature and humidity is most widely accepted to assess human exposure to extreme heat (Brouillet and Joussaume 2019). The human temperature comfort decreases with the increase of temperature and relative humidity, and vice-versa. It is also related to the evaporative cooling of the human body or physical homeostasis (Kjellstrom et al. 2009; Buzan et al. 2015). High temperature and humidity together cause human discomfort, which may lead to heatstroke. Sweating is an essential body mechanism by which the human body can transport away metabolic heat. At a higher dry bulb temperature and relative humidity, the human body's heat exchange process is ceased, which results in accumulating excessive temperature in the human body (Budd 2008) and accelerates the rate of morbidity and mortality (Basu and Samet 2002). Therefore, HI estimated based on both dry bulb temperature, and relative humidity is most widely accepted to evaluate heat extremes.

Though heat extreme-related casualties are increasing globally, the growing rate of health consequences is much higher in developing countries, mainly densely populated countries, due to higher exposure. South Asia is one of the most vulnerable regions regarding public health exposure to temperature rise (Singh et al. 2016). Climate models projected more frequent and intense heat extremes in the region than in many other regions of the globe (UN ESCAP 2015; Im et al. 2017). Bangladesh, located in South Asia, is enormously susceptible to global climate change (Huq 2001; Rahman and Islam 2019; Salam and Islam 2020). The country has experienced some recent heat extreme occurrences, which caused high mortality, especially the death of males and people older than 65 years (Burkart et al. 2014). Heat extreme-related mortality rate has increased by $20 \%$ in Bangladesh over the past decade (Nissan et al. 2017). Climate change might increase the frequency and intensity of heat exposure in the forthcoming period (Kirtman and Coauthors 2013). Battisti and Naylor (2009) reported an increase in heat extremes in tropical and subtropical regions in the future. Future forecasts of climate change scenarios in Bangladesh demonstrated a higher occurrence of extreme heat (Nissan et al. 2020). The minimum heat exposure of consecutive 3 days might exceed up to 10 days in the country in the future (Nissan et al. 2017).

Although many researchers have investigated the changes and variabilities of Bangladesh's climate at the regional and country levels (Islam et al. 2017, 2020; Salam et al. 2020), the climate-health relationship studies in the country are very rare (Rahman et al. 2019; Nissan et al. 2020). The previous studies are focused mainly on $\mathrm{HI}$ anomaly assessment (Rajib et al. 2011), extreme temperature variability (Rakib 2013), HI trends in southwest Bangladesh (Rakib 2018), effects of heat extreme (Burkart et al. 2014), mortality due to high temperature (Burkart et al. 2011), and heatwave prediction (Nissan et al. 2017). No attempt has been taken to quantify the spatiotemporal change in historical (observed) and projected $\mathrm{HI}$ in different climatic regions of Bangladesh. This study intends to fill this research gap by quantifying the HI's spatiotemporal changes in Bangladesh due to climate change. The information generated in this study can be used for adaptation planning and reducing climate change impacts on disease and death, particularly the large number of marginally poor people involved in agriculture and construction and exposed to heat extremes in the country (McGregor et al. 2015; Havenith and Fiala 2016).

\section{Materials and methods}

\subsection{Study area}

Bangladesh, a low-lying subtropical South Asian country, has a land area of $147,570 \mathrm{~km}^{2}$ (Rahman and Islam 2019). Three dominant seasons are prevailing in Bangladesh, pre-monsoon hot summer (March to May), monsoon humid summer (June to August), and post-monsoon (September to November) and dry winter (December to February) seasons. The annual mean rainfall is approximately $2,400 \mathrm{~mm}$, of which about $75 \%$ occurs in the monsoon from June to September.

Long-term daily mean relative humidity, minimum temperature, maximum temperature, and evapotranspiration across Bangladesh are $80 \%, 21.39^{\circ} \mathrm{C}, 29.94^{\circ} \mathrm{C}$, and $3.72 \mathrm{~mm} \mathrm{~d}^{-1}$, respectively (Salam and Islam 2020). January is the coldest, and April to October is the hot months in Bangladesh.

Banglapedia (2014) demarcated Bangladesh into seven climatic sub-regions based on climate, land use patterns, and hydrogeologic settings (Figure 1). There is spatial variability 
Figure 1 Map showing the location of the study area and meteorological stations along with climatic zones in Bangladesh

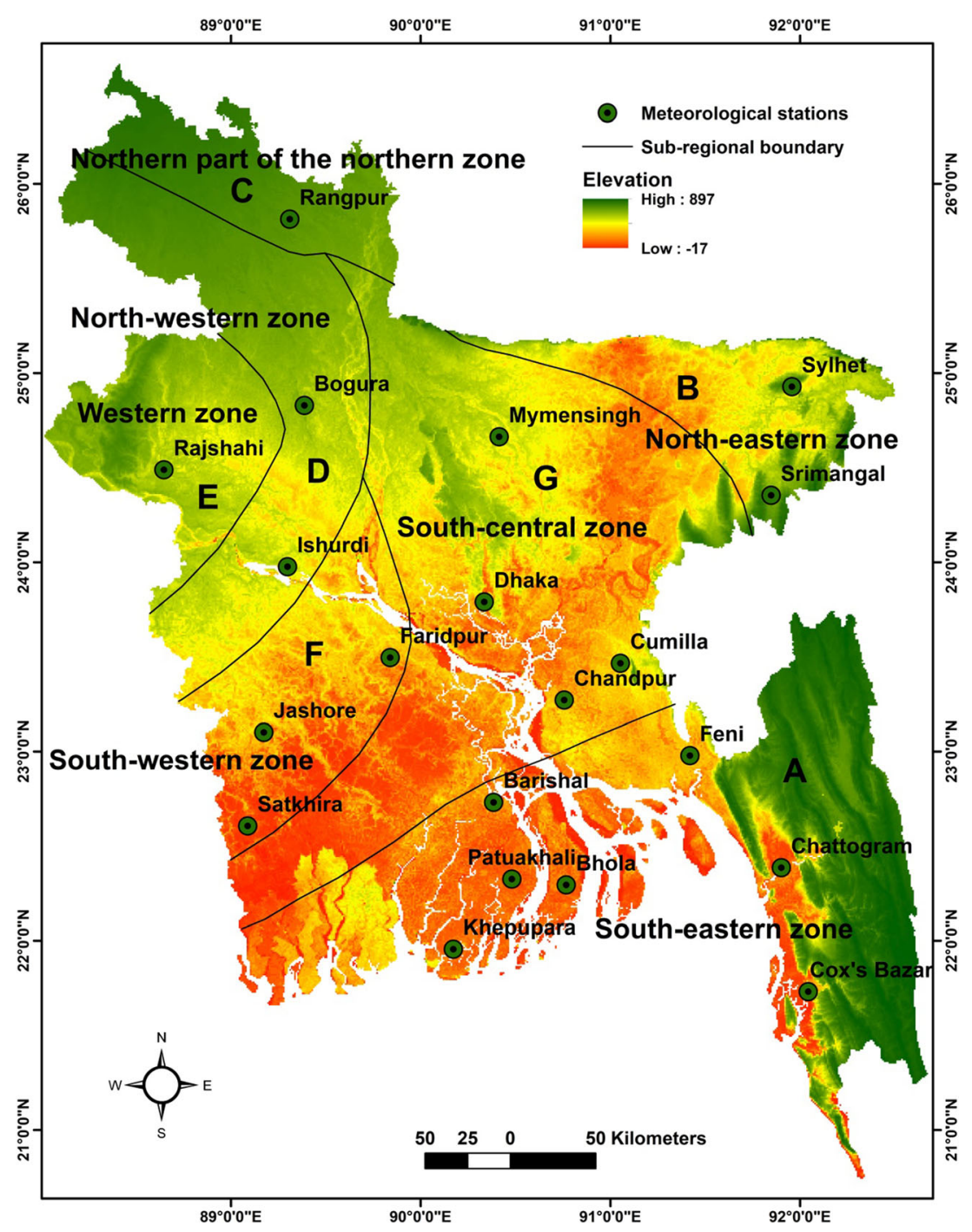

in climate in Bangladesh (Ghose et al. 2021). The western zone of the country is relatively drier compared to other areas (Islam et al. 2017).

\subsection{Data description}

Bangladesh Meteorological Department (BMD) operates only 43 weather stations throughout the country. Weather stations across the country are not uniformly distributed. They are mostly concentrated in the southeastern and south-central regions. Many of the stations are set up after the 1990s and do not have a long-term record (www.bmd.gov.bd). Due to these shortcomings of long-term data availability, only 20 weather stations were selected to estimate the HI for the period 19852015. These selected stations encompass the seven climatic sub-regions of the country. The period between 1985 and 2015 is regarded as the warmest period on record (IPCC 2019). The global average surface temperature rising was 0 . $87^{\circ} \mathrm{C}$ during $1985-2013$ relative to $1850-1900$ (IPCC 2013).
For that reason, the daily climate dataset for the period 19852015 was used as the historical period.

Daily dry-bulb temperature $(\mathrm{T})\left({ }^{\circ} \mathrm{C}\right)$ and mean relative humidity (R) (\%) data of 20 stations were acquired from the BMD. The missing data at all the stations were found less than $5 \%$. The missing data were filled using the past data of the respective days or the data from the neighbouring stations after consulting with the expert of BMD. The BMD follows the World Meteorological Organization (WMO) guideline for weather dataset acquisition and record archiving. Nonetheless, a homogeneity test and autocorrelation of the dataset were performed to reveal any anomaly in the dataset (Islam et al. 2020). All the datasets were passed the quality control test conducted by BMD staff.

\subsection{Statistical downscaling model}

The statistical downscaling model (SDSM) usually develops the statistical relationship of regional predictors with 
forecasters utilizing the multiple linear regression model (Wilby and Dawson 2007). Typically, this relationship is formed between station data (e.g., temperature) and NCEP variable, as a proxy of GCM simulation, for the study period. The GCM simulations of NCEP variables are then used in SDSM for historical simulation and future projections of the variable at the station level. In this study, two variables, temperature and relative humidity, were downscaling at 20 stations in Bangladesh (details in Section 2.2). The GCM data of CanESM2, obtained from the Canada Climate change site, was used for this purpose. The inputs of the downscaling model were selected by screening 26 NCEP variables based on their association with station data. The GCM simulations of the selected NCEP variables for three RCP scenarios (very low emission-RCP 2.6, medium emission-RCP 4.5, and a very high emission-RCP 8.5 ) were used to downscale the future projections of temperature and relative humidity for those three scenarios.

The SDSM was calibrated with $70 \%$ of historical data and validated with the rest (30\%). The performance of the downscaling model was evaluated using the coefficient of determination $\left(\mathrm{R}^{2}\right)$, standard error (SE), and Durbin Watson (DW) tests. All the statistical tests have given satisfactory results (Table S1), indicating the ability of downscaling models developed in this study in downscaling temperature and relative humidity. Figure S1 illustrates the key steps used in this SDSM. The downscaled temperature and relative humidity data were finally used to simulate HI for the three RCPs for the period of 2041-2070.

The CanESM2 model can generate reasonable projections of worldwide climate variability (Arora et al. 2011; Wang and Zhang 2019; Chavaillaz et al. 2019; Yengoh and Ardö 2020). The result produced by the CanESM2 model is found reliable based on its historical performance and accuracy (Javaherian et al. 2021). Therefore, this model has been extensively used for climate projections in different regions, including South Asian countries (Das and Umamahesh 2016; Khadka and Pathak 2016; Dissanayaka 2017; Attique 2018; Saddique et al. 2019; Shafiq et al. 2019; Azam et al. 2020).

The Intergovernmental Panel on Climate Change (IPCC) has regarded the GCMs as an important tool for assessing future climatic impacts. SDSM has been recognized as an efficient technique for downscaling GCM simulation (Gagnon et al. 2005). Therefore, the present study utilized SDSM for downscaling CanESM2 simulations at the station level for the estimation of HI.

\subsection{Estimation of heat index}

For estimating the HI using the CanESM2 model, the temperature data collected from BMD were converted from ${ }^{\circ} \mathrm{C}$ to ${ }^{\circ} \mathrm{F}$ using the following Eq. (1) for easy calculation of the HI:
$T_{(o F)}=T_{(o C)} \times 1.8+32$

The historical HI was computed from relative humidity (\%) and temperature $\left({ }^{\circ} \mathrm{F}\right)$ using Eq. (2).

$H I=c_{1}+c_{2} T+c_{3} R+c_{4} T R+c_{5} T^{2}+c_{6} R^{2}+c_{1} T^{2} R+c_{8} T R^{2}=c_{9} T^{2} R^{2}$

where the HI denotes heat index (in degrees Fahrenheit); $\mathrm{T}$ indicates ambient dry-bulb temperature (in degree Fahrenheit); $\mathrm{R}$ means relative humidity (percentage value between 0 and 100); and $C_{1}=-42.379 ; C_{2}=2.04901523$; $C_{3}=10.14333127 ; C_{4}=-0.22475541 ; C_{5}=-6.83783 \times 10^{-3}$; $\mathrm{C}_{6}=-5.481717 \times 10^{-2} ; \mathrm{C}_{7}=1.22874 \times 10^{-3} ; \mathrm{C}_{8}=8.5282 \times 10^{-4} ;$ $\mathrm{C}_{9}=-1.99 \times 10^{-6}$

The HI, used in this study, integrates bulb temperature and humidity and estimates health exposure (HE) to heat extreme (Anderson et al. 2013; Modarres et al. 2018). The HI was demarcated into four classes, e.g., caution $\left(80-90^{\circ} \mathrm{F}\right)$, extreme caution $\left(90-105^{\circ} \mathrm{F}\right)$, danger $\left(105-130^{\circ} \mathrm{F}\right)$, and extreme danger $\left(>130^{\circ} \mathrm{F}\right)$ (Belding 1970; Modarres et al. 2018). The HI for the historical period 1985-2015 was estimated from observed data, while it was calculated for the future period using GCM projected data for the period 2041-2070.

\subsection{Modified Mann-Kendall test}

Different techniques are available for assessing the trend of climatic variability. The scholars used Mann-Kendall (MK) (Mann 1945; Kendall 1975) and modified MK (MMK) tests for detecting trends (Vousoughi et al. 2013; Jhajharia et al. 2014; Dinpashoh et al. 2014; Zamani et al. 2017; Praveen et al. 2020; Islam et al. 2021). The MK test has the problem of serial correlation, which may affect the trend result. Yue and Wang (2004) introduced the MMK test for eliminating the serial correlation effect on test significance. MMK test provides a more accurate assessment of the significance of the existing trends because the influence of the existing trend on sample serial correlation estimation has been effectively limited (Hamed and Rao 1998). The nonparametric MMK test was utilized in this study to assess the HI trends. The original equation of the MK test (Mann 1945; Kendall 1955) statistics (S) is expressed by following Eqs. 3-4:

$$
\begin{aligned}
& S=\sum_{i=1}^{n-1} \sum_{j=i+1}^{n} \operatorname{sgn}\left(X_{j}-X_{i}\right) \\
& \operatorname{sgn}(\theta)=\left\{\begin{array}{cl}
1 & \text { if } \theta>0 \\
0 & \text { if } \theta=0 \\
-1 & \text { if } \theta=0
\end{array}\right.
\end{aligned}
$$

Values of S indicate the direction of decreasing or increasing trend. The variance (Rahman et al. 2017) of S is followed by the Eq. 5 : 
$V(S)=\frac{n(n-1)(2 n+5)-\sum_{i=1}^{n} t_{i} i(i-1)\left(2 t_{i}+5\right)}{18}$

$\mathrm{V} *(\mathrm{~S})$, is modified by Yue and Wang (2004) and given by the following Eq. 6:

$V^{*}(S)=V(S) \cdot \frac{n}{n^{*}}$

The correction factor is denoted by $\mathrm{n} / \mathrm{n}^{*}$ and expressed (Bayley and Hammersley 1946) by following Eq. 7:

$\frac{n}{n^{*}}=1+2 \cdot \sum_{k=1}^{n-1}\left(1-\frac{k}{n}\right) \cdot \rho_{k}$

Test statistic $\mathrm{Z}$ is calculated by following Eq. 8:

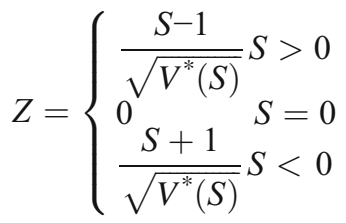

Positive $\mathrm{Z}$ values mean increasing trend and negative $\mathrm{Z}$ values mean decreasing trend. "modifiedmk" package of $\mathrm{R}$ statistical software (v3.5.3) was used for performing the MMK test.

\subsection{Sen's slope estimator}

Sen (1968) proposed the method for measuring the change per time, which is given by the following equation:

$\beta_{i}=\frac{x_{j}-x_{k}}{j-k}, \forall k \leq j$ and $i=1,2, \ldots \ldots, N$

where $\beta$ is the slope between $x_{j}$ and $x_{k}$. The median $\mathrm{N}$ values of $\beta_{i}$ provides the Sen's slope of estimator $\beta$.

$\beta=\left\{\begin{array}{l}\frac{\beta N+1}{2}, \text { if } N \text { is odd } \\ \frac{\left(\frac{\beta N}{2}+\frac{\beta N+2}{2}, \text { if } N \text { is even }\right.}{2}\end{array}\right.$

The present study has utilized Sen's slope estimator for identifying the magnitude of the change of the historical HI (Sen 1968; Islam et al. 2019; Zinat et al. 2020).

\subsection{Simple linear regression}

Linear regression was used for exploring the relationship between two variables of continuous data. The following equation is expressed the statistical form of linear regression:

$Y=a+b X$ where $\mathrm{Y}$ denotes the dependent variable, $\mathrm{a}$ is constant, $\mathrm{b}$ means the coefficient and slope of the regression line, and $\mathrm{X}$ demonstrates the independent variable.

Here, the historical $\mathrm{HI}$ is used as a dependent variable and time (years) as an independent variable. The value of the correlation coefficient ( $\mathrm{r}$ ) varies from -1 to 1 . The absolute 1 denotes a strong correlation, and a value near zero indicates a weak correlation. This simple linear regression method has been applied to monitor the monotonic changes in the historical HI in this study

\section{Results}

\subsection{Spatiotemporal changes of the historical and projected HI}

Figures 2 and 3 show the temporal changes of the HI between hot summer and humid summer, respectively, in the projected period compared to the historical period. Figure 2 demonstrates that the HI values ranged from $88^{\circ}-92^{\circ} \mathrm{F}$, indicating the extreme caution in the northern, western, south-central, and southeastern regions. In the northeastern region, the HI values range from $83^{\circ}-85^{\circ} \mathrm{F}$, also indicating the caution HI. The projected $\mathrm{HI}$ slightly decreased than the historical $\mathrm{HI}$ in the southwestern region. On the contrary, considerable declination in $\mathrm{HI}\left(80^{\circ}-84^{\circ} \mathrm{F}\right)$ was noticed in the northwestern region compared to the historical $\left(85^{\circ}-88^{\circ} \mathrm{F}\right)$ period during the hot summer (March-May). All the regions showed caution $\mathrm{HI}$ for the historical period $\left(\mathrm{HI}<90^{\circ} \mathrm{C}\right)$, except in the southwest (extreme caution $\mathrm{HI}$ ). Figure 3 shows increase in $\mathrm{HI}$ in the northern, northeastern, and southcentral regions during humid summer (June-August). The rest of the regions would experience less HI than historical HI. Like the hot summer, the northwestern region would experience considerable declination of the HI compared to historical HI. For both hot summer and humid summer, the projected scenarios' ascending order in increasing $\mathrm{HI}$ is $R C P 8.5>R C P 4.5>R C P 2.6$.

The long-term station-wise mean annual variations of $\mathrm{HI}$ for hot summer and humid summer are shown in supplementary Figure of S2. Both hot summer and humid summer showed nearly the same projected HI for RCP 2.6, RCP 4.5, and RCP 8.5. The projected scenarios of RCP2.6, RCP 4.5, and RCP 8.5 for $\mathrm{HI}$ were higher than the historical $\mathrm{HI}$ in all the stations except for Bogra, Faridpur, and Chattogram stations for hot summer (Figure S2a) and Bogra, Khepupara, Satkhira, and Cox's Bazar stations for humid summer (Figure S2b). It is shown in Figure S2 that Bangladesh would be facing higher $\mathrm{HI}$ in humid summer compared to hot summer in the future.

The probability density function (PDF) plot was used to investigate the distributional change mean annual $\mathrm{HI}$ for the historical and projected periods. The PDFs of the HI for the seven climatic zones of Bangladesh predicted the potentially 
Figure 2 Temporal variation of hot summer for the seven climatic regions of Bangladesh
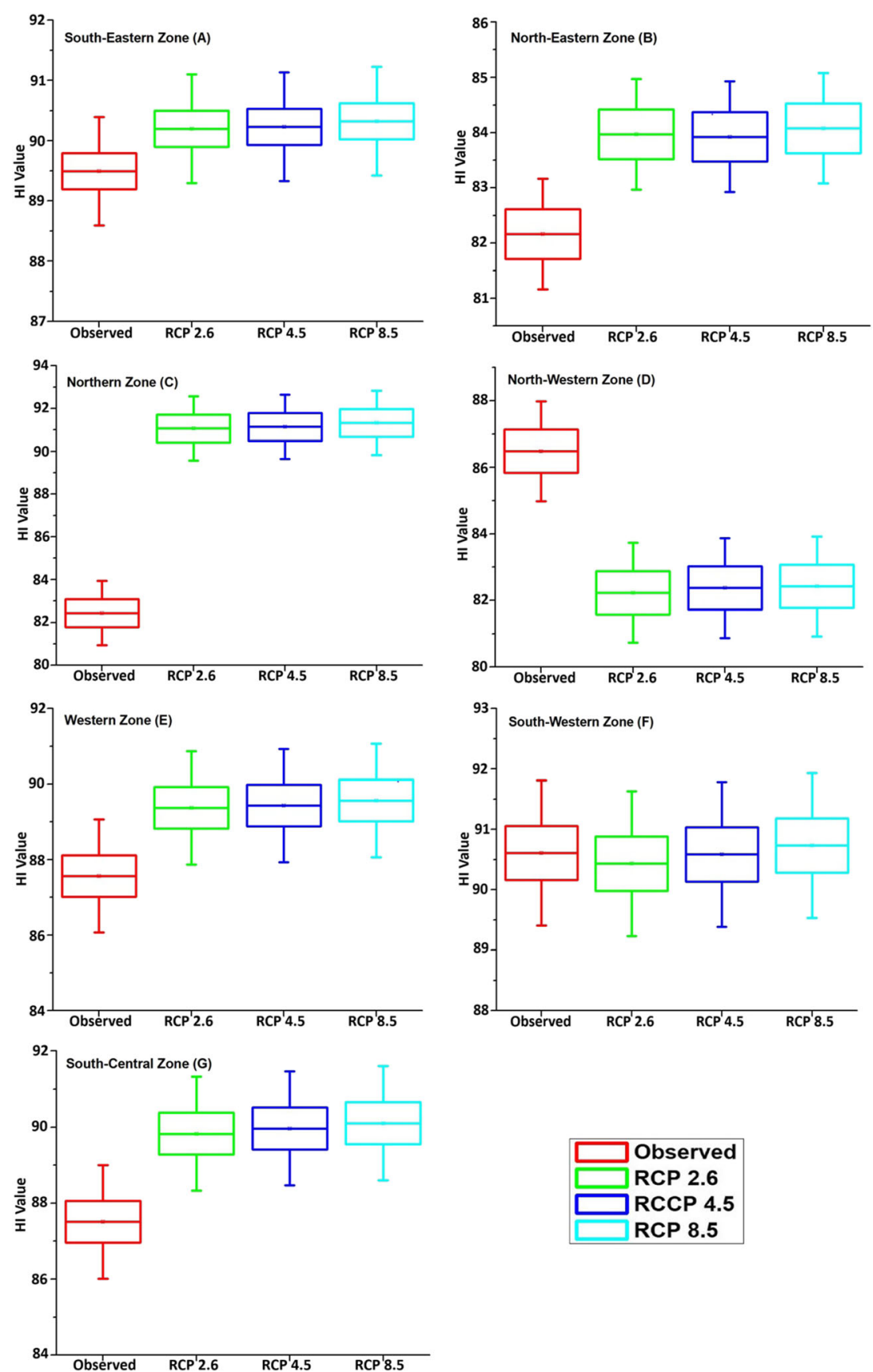

significant changes (Figure 4). Rightward shifting of the shape is a sign of the future-increasing trend of the mean annual HI. The future-expanding pattern in the $\mathrm{HI}$ in different zones can be ranked as Zone C (Northern), followed by Zone B (Northeastern), Zone G (South-central), Zone E (South-eastern), Zone F (South-western), Zone A (Western), and Zone D (North-western). Among these zones, Zone D (Northwestern) showed a remarkable decrease in $\mathrm{HI}$ in the future.

The spatial changes of the HI during the historical (19852015) and projected period (2041-2070) for three scenarios are presented in Figure 5. The results show that the HI values in the northern zone would increase from $81-84^{\circ} \mathrm{F}$ to $85-86^{\circ} \mathrm{F}$ compared to the historical (observed) HI, indicating increasing temperature and relative humidity in the north. The $\mathrm{HI}$ of southwestern, south-central, and western zones also showed an increase. Surprisingly, the HI values would decrease in a few stations like Chattogram and Faridpur.

Figure 6 demonstrates that most regions of Bangladesh, exposed to cautious conditions $\left(80<\mathrm{HI}<90^{\circ} \mathrm{F}\right)$ in the historical period, would experience a cautious condition of HI $\left(80<\mathrm{HI}<90^{\circ} \mathrm{F}\right)$ in the projected period during the hot summer season. The western parts especially southeastern, south-central, and southwestern regions would experience more than $92^{\circ} \mathrm{F}$ but less than $94^{\circ} \mathrm{F}$ HI (extreme caution) for all the 
Figure 3 Temporal variation of humid summer for the seven climatic regions of Bangladesh
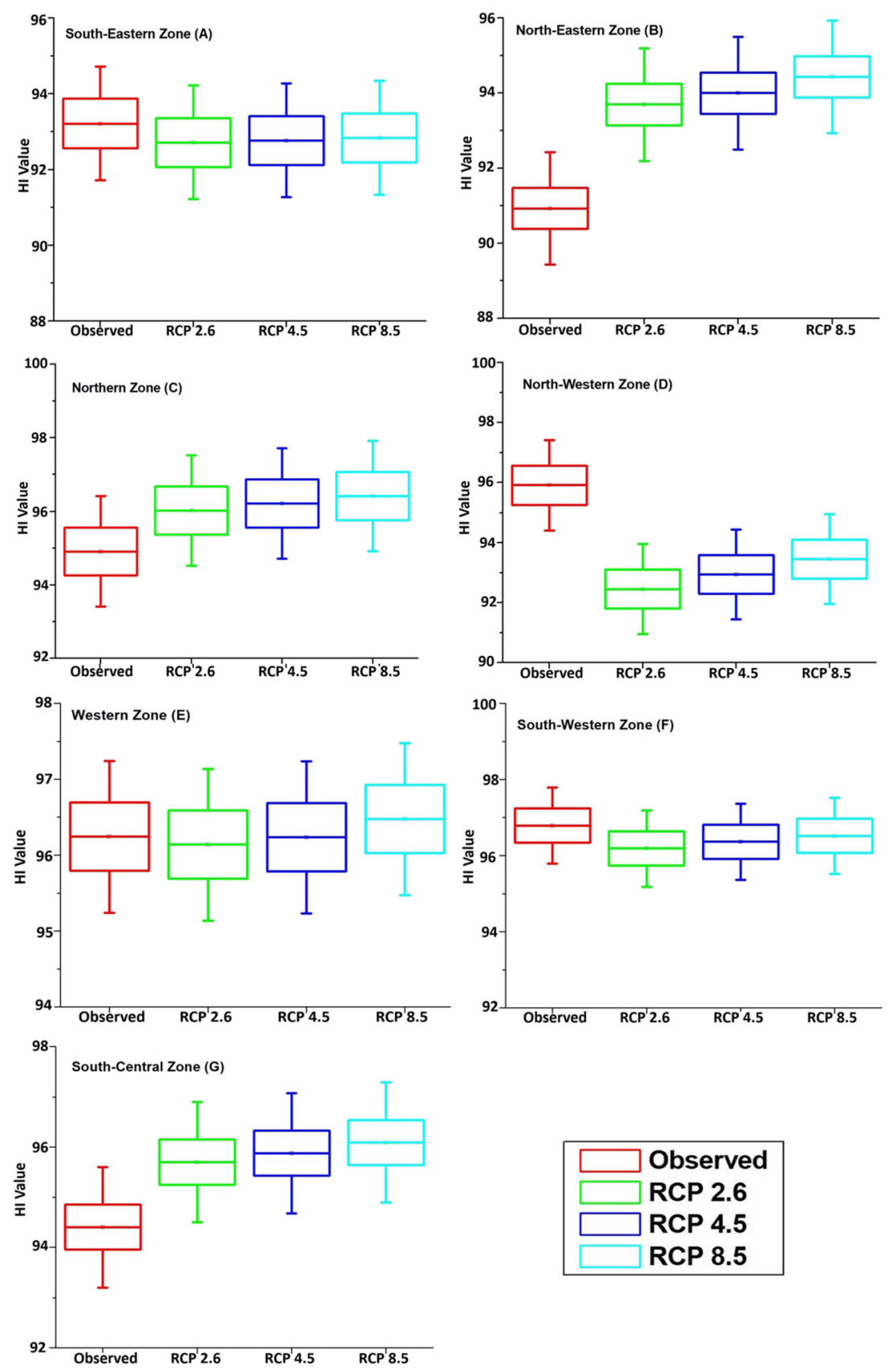

scenarios during the hot summer season. Like the temporal distribution, spatial distribution also depicted higher HI during humid summer than that for hot summer (Figure 6). In the humid summer season, most parts of Bangladesh were exposed to extreme caution conditions $\mathrm{HI}>90-105^{\circ} \mathrm{F}$ during the historical period. Unlike the historical period (HI ranged from $89-92^{\circ} \mathrm{F}$ ), the northeastern region would experience higher $\mathrm{HI}\left(92-94^{\circ} \mathrm{F}\right)$ in the future for all scenarios. On the contrary, the southeastern part of the southeastern (A zone) region would expose to the same HI level as the historical period. Most of Bangladesh that experienced extreme condition in the past would also experience extreme condition in the future $\left(94-96^{\circ} \mathrm{F}\right.$ and $\left.96-98^{\circ} \mathrm{F}\right)$ during humid summer.

The HI and the rate of HI change for the historical period of 1985-2015 are shown in Figure 7. The figure demonstrates that HI has increased significantly $(\mathrm{p}>0.01,0.05,0.1)$ in most of the country except (insignificant decreasing trend) some parts in the southwestern region and the northern and northeastern of zone G (south-central region) (Figure 7a). Northern and southeastern regions experienced the most significant ( $>0.01$, MMK $Z$ value ranged from 6-7) increasing trend in HI compared to other regions (Figure 7a). The rate of change in $\mathrm{HI}$ was from -0.01 to $0.03^{\circ} \mathrm{F}$ per decade 

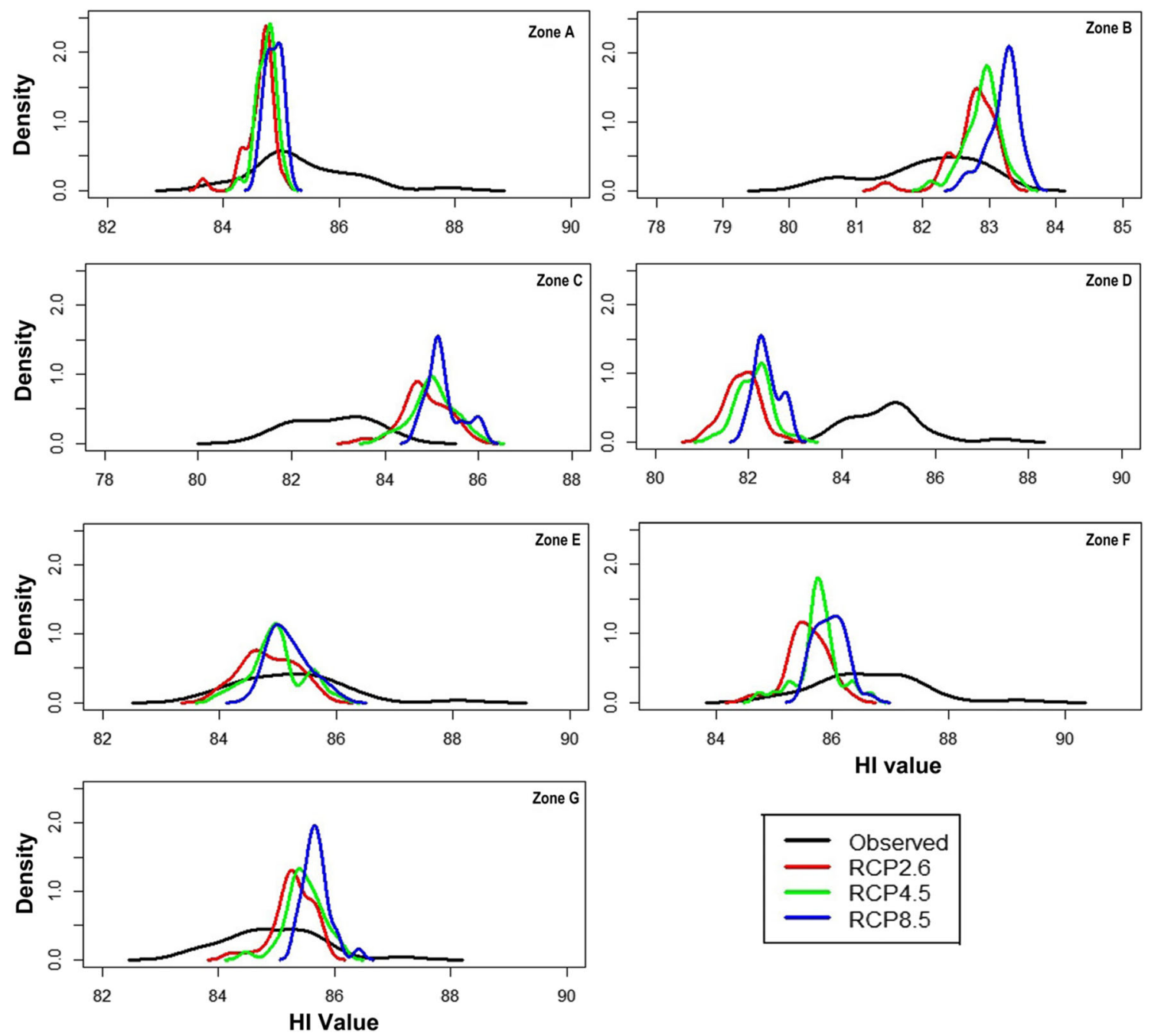

Figure 4 Probability density function of the mean annual $\mathrm{HI}$ for the seven climatic zones of Bangladesh

(Figure $7 b$ ). The same results were found using the linear regression model (Figure S3).

\section{Discussions}

The present study investigated the changes in seasonal and spatial HI for historical and projected periods across Bangladesh. This study represents a crucial step to quantify temporal and spatial changes of HI over Bangladesh under three different future climate change scenarios. Most of the earlier works in Bangladesh are based on the maximum temperature and minimum temperature changes, the temporal pattern of extreme temperature condition, heatwave, etc. (Rakib 2013; Fahad et al. 2018; Khan et al. 2019; Nissan et al. 2020). However, Fahad et al. (2018) used a statistical downscaling model to project exposure to rising temperature in Bangladesh. They found that northern Bangladesh will be more affected due to heat extremes. The present study also found that the northern region would be more vulnerable to HI during the hot summer season due to increased temperature and precipitation (a high precipitation rate accelerates the percentage of relative humidity), which is consistent with the results of this study. Rajib et al. (2011) showed increases in $\mathrm{HI}$ in Bangladesh's southwestern and northwestern regions from 1961-2010. This study also reported increasing $\mathrm{HI}$ in the northern (contrary to Rajib et al. 2011), northeastern, and south-central regions (consistent with Rajib et al. 2011) of the country during the historical period (1985-2015). The most probable reason for the increasing the $\mathrm{HI}$ is unfavourable climatic conditions, environmental pollution, and the lessening and irregularity of rainfall, causing a rising trend in humidity in northwestern, central, and eastern Bangladesh.

The right shift of the PDFs suggests that the onset of an increasing trend in HI mean and extremes and rare heatwaves in the future (Modarres et al. 2018). This study revealed that the northern and northeastern regions have the highest probability of increasing HI. At the same time, 
Figure 5 Spatial changes of the HI during the observed (19852015) and projected period (2041-2070) under three different RCP scenarios over Bangladesh

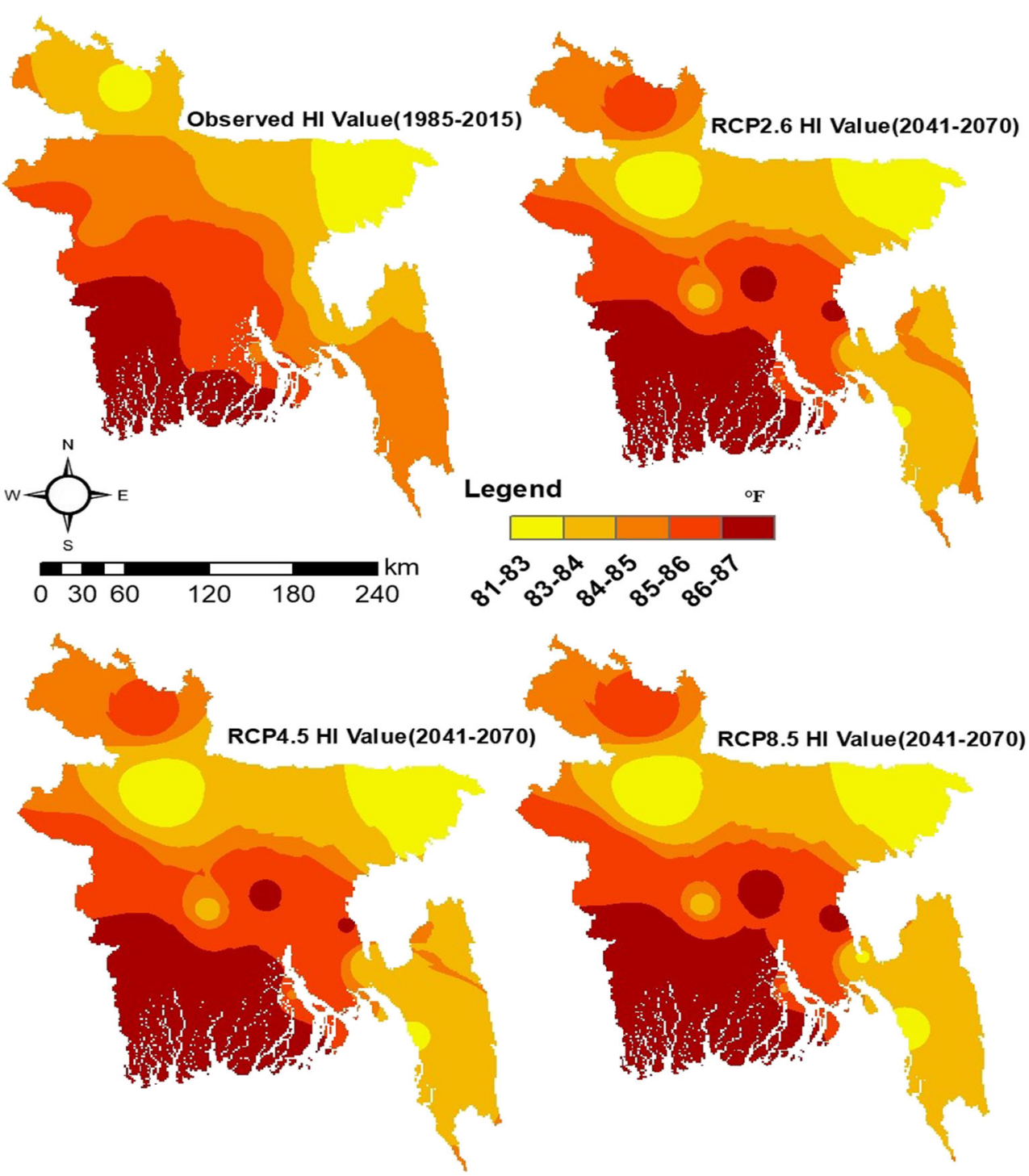

the northwestern region might experience a decreasing rate of $\mathrm{HI}$ in the future period. The cause of increasing $\mathrm{HI}$ is the rising humidity in the northwestern, central, and eastern regions due to unfavourable climatic conditions, environmental pollution, and the abatement and irregularity of rainfall (Rajib et al. 2011). In this study, a remarkable change of the $\mathrm{HI}$ is detected in Barishal during the humid summer for three different future scenarios. In the far future, the HI value may turn into a dangerous condition in Barishal. Besides, the study also indicates that the HI would increase at an alarming rate at Rangpur, Chandpur, Cumilla, and Rajshahi. Surprisingly, HI would decrease at Bogra, Chattogram, and Faridpur in the future period. The temperature for higher RCP showed a decrease and rainfall to increase in Chattogram and Faridpur, leading to a reduction of the HI of these two stations (Alamgir et al. 2019; Islam et al. 2019; Rahman and Islam 2019).
Rakib (2013) demonstrated that the HI values are within a comfortable limit during the dry season. But it increases rapidly during summer, which is similar to our finding. For example, in hot summer, Rangpur would experience a change in $\mathrm{HI}$ at least $10 \%$ in the future (2041-2070) compared to the historical period. In contrast, Barishal would show the highest $\mathrm{HI}$ in humid summer as it is located near the coast. The high humidity is the cause of the elevated HI at Barishal.

Prolonged exposure to such $\mathrm{HI}$ conditions may result in epidemiological problems such as human health hazards (Hansen et al. 2008). Although the physiology of the human body may be adapted to a long-term change in climate (Hondula et al. 2015; Kjellstrom et al. 2016), the outcomes recommend an urgent requirement for health care system guideline, robust early warning scheme, and healthcare plans to cope with the rising temperature. The rising HI may lead to a rise in heat-related death 
RCP 4.5 HI (2041-2070)
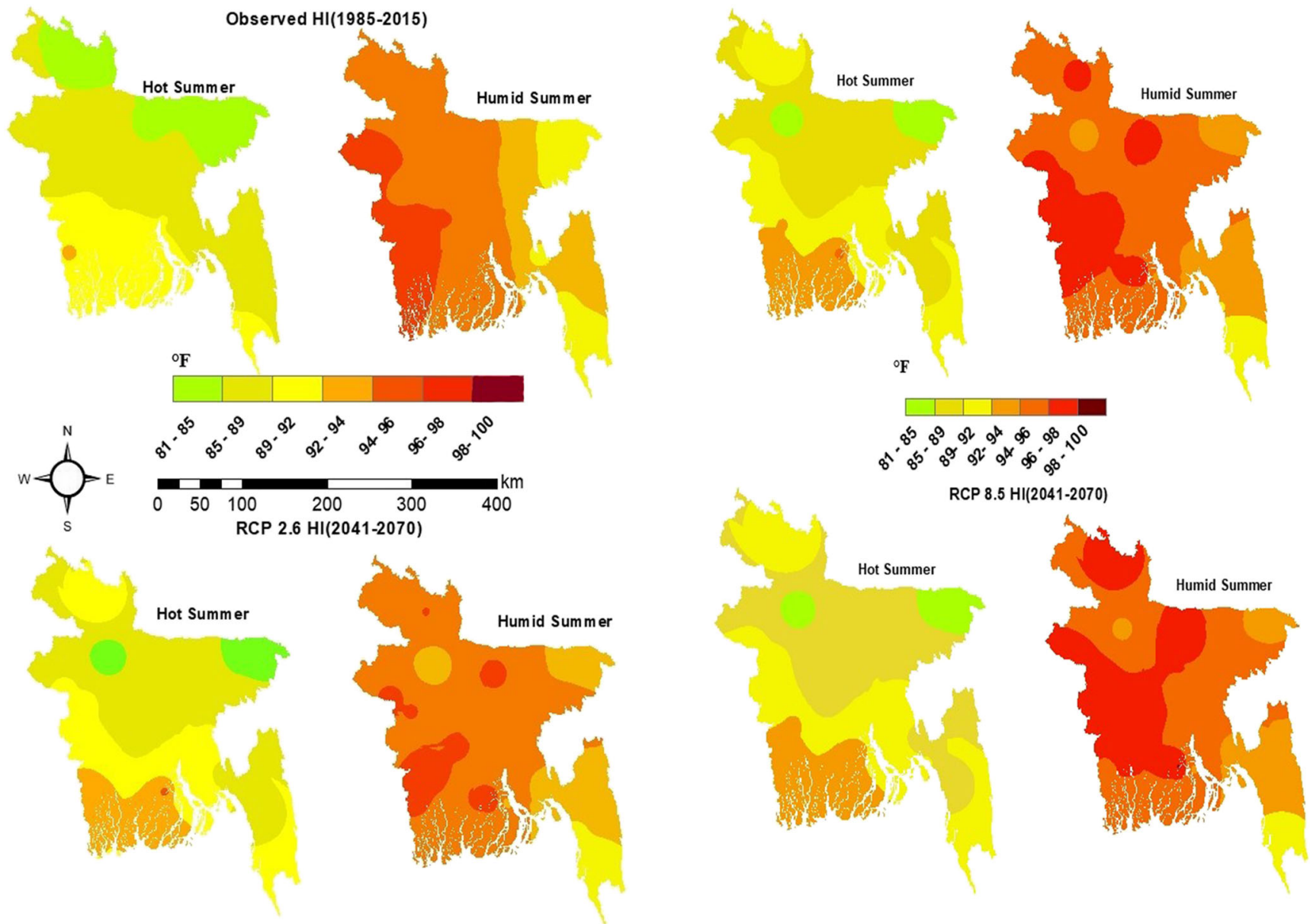

Figure 6 Seasonal changes of the observed HI (1985-2015) and the projected HI (2041-2070) across Bangladesh for hot summer and humid summer under three different scenarios

(Bowler 2005; Fischer et al. 2012; Hansen et al. 2012; Buzan et al. 2015; Li et al. 2018; Pal and Eltahir 2016), the risk of novel infectious diseases like Coronavirus (Shammi et al. 2020), air conditioning demand, human errors in the workplace, and an increasing trend of accidents. This indicates the need to shift work hours to avoid severe circumstances (Kjellstrom et al. 2016; Mora et al. 2017; Bodrud-Doza et al. 2020). The increase in temperature and relative humidity over Northeastern Indian states, including Assam bordering Bangladesh, and the rising temperature and changes in rainfall pattern/ humidity may cause higher cases of vector-borne diseases (Jhajharia et al. 2013).

The present study has only employed the CanESM2 for future projection of the HI. The future study should consider more than one GCM and explore the best GCM for projecting the climate variability of Bangladesh. Station data were collected from only 20 meteorological stations for HI projections. The future study should collect data from more stations and project the HI from 2021. In the future, a quantitative risk assessment based on the $\mathrm{HI}$ in various climatic zones of Bangladesh at the regional and global scales should be performed, considering various demographic information.

\section{Conclusion}

The present study intends to show the historical and future spatiotemporal changes in $\mathrm{HI}$ in seven climatic regions of Bangladesh. The HI in Bangladesh varies at the seasonal scale and among the climatic zones. The projected results revealed that HI's risk in Bangladesh would be more severe during humid summer than that of the hot summer season for all the three RCPs of RCP 2.6, RCP 4.5, and RCP 8.5 scenarios at both the temporal and spatial scales. This study has identified future hotspots of HI, particularly in the country's northern, northeastern, and south-central regions. The future-expanding pattern in the $\mathrm{HI}$ in different zones can be ranked as Zone $\mathrm{C}$ (northern). The outcomes obtained in this study by considering temperature with relative humidity can be regarded as more reliable for 
Figure 7 Modified MK test $Z$ value (a) and Sen's slope trend (b) of the historical HI

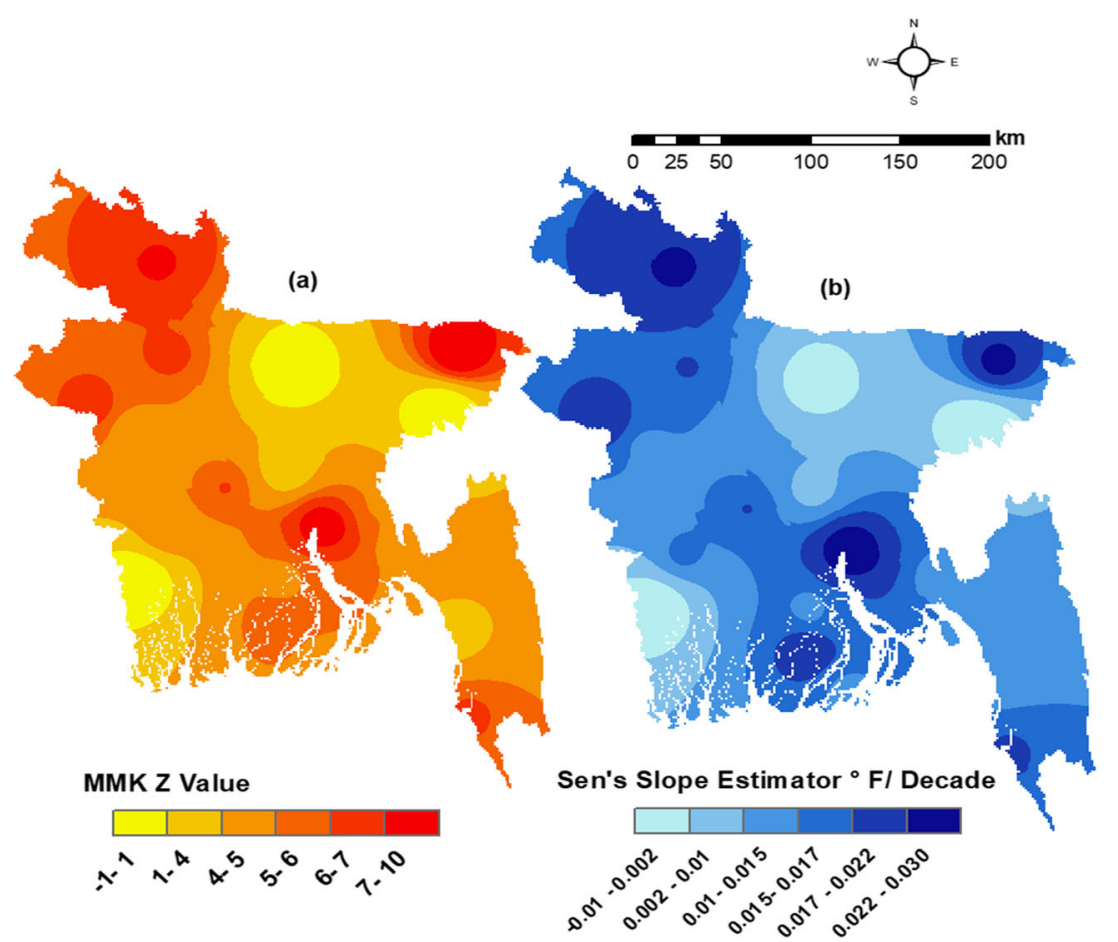

emerging emergency management strategy planning and early warning schemes. The results would help the planners and policymakers formulating and implementing adaptation strategies for minimizing the effects of future climate change. These results are also crucial for policymakers to take initiatives for coping with this alarming risk of heat extremes by preparing region-wise and season-specific different contingency plans. This was the first attempt to quantify the spatiotemporal change of the historical and projected HI in various climatic regions of Bangladesh. The inclusion of relative humidity with temperature for the projection of $\mathrm{HI}$ has made the estimation more realistic for a humid country like Bangladesh.

Supplementary Information The online version contains supplementary material available at https://doi.org/10.1007/s00704-021-03705-x.

Acknowledgements We greatly acknowledge the Bangladesh Meteorological Department (BMD) for proving the necessary datasets in this work.

Author contribution ARMTI conceptualized the study; MBR analyzed the data; MBR performed the GIS-based mapping; ARMTI, AT, SMI, $\mathrm{JM}$, and $\mathrm{ZH}$ interpreted the results; MBR and AT searched the relevant literatures and drafted the initial manuscript. First extensive review and edits were performed by UH. All authors subsequent reviewed and edited for its clarity. Besides, a critical review was done by UH, ZH, SS, JM, and ARMTI. Final version was approved by all the authors.
Funding The authors extend their appreciation to the Deanship of Scientific Research at King Khalid University for funding this work through Research Group under grant number (R.G.P.2 /194/42).

Data availability The time series datasets supporting the conclusions of this article will be made available upon request on the corresponding author.

\section{Declarations}

Ethical approval Not applicable.

Consent to participate Not applicable.

Consent to publish Not applicable.

Conflict of interest The authors declare no competing interests.

\section{References}

Alamgir M, Ahmed K, Homsi R, Dewan A, Wang JJ, Shahid S (2019) Downscaling and projection of spatiotemporal changes in temperature of Bangladesh. Earth Syst Environ 3(3):381-398

Anderson GB, Bell ML, Peng RD (2013) Methods to calculate the heat index as an exposure metric in environmental health research. Environ Health Perspect 121:1111-1119. https://doi.org/10.1289/ ehp. 1206273

Arora V, Scinocca J, Boer G, Christian J, Denman K et al (2011) Carbon emission limits required to satisfy future representative concentration pathways of greenhouse gases. Geophys Res Lett 38(1-6): L05805. https://doi.org/10.1029/2010GL046270

Attique R (2018) Comparison between statistical and dynamical downscaling of rainfall under Representative Concentration Pathways 
scenarios over the Gwadar-Ormara basin, Pakistan, essay:83341, http://essay.utwente.nl/83341/

Azam MI, Guo J, Shi X, Yaseen M, Mohammed A, Lü H, Dai L (2020) Evaluation of statistical model for future precipitation and temperature in drainage area of Jhelum river, Pakistan. Pakistan J Agric Sci, 57(3):605

Ballester J, Rodo X, Robine JM, Hermann FR (2016) European seasonal mortality and influenza incidence due to winter temperature variability. Nat Clim Chang 6:927-930. https://doi.org/10.1038/ NCLIMATE3070

Banglapedia (2014) Drought in Bangladesh. http://en.banglapedia.org/ index.php? Accessed 12 Feb 2019

Basu R, Samet JM (2002) Relation between elevated ambient temperature and mortality: a review of the epidemiologic evidence. Epidemiol Rev 24(2):190-202

Battisti DS, Naylor RL (2009) Historical warnings of future food insecurity with unprecedented seasonal heat. Science 323(5911):240-244

Bayley GV, Hammersley JM (1946) The effective number of independent observations in an autocorrelated time series. J R Stat Soc 8(1B):184-197

Belding HS (1970) The search for a universal heat stressindex. In: Hardy JD, Gagge AP, Stolwijk JAJ (eds) Physiological and behavioral temperatureregulation. CC Thomas, Springfield, pp 193-202

Blazejczyk K, Epstein Y, Jendritzky G, Staiger H, Tinz B (2012) Comparison of UTCI to selected thermal indices. Int $\mathrm{J}$ Biometeorol 56:515-535. https://doi.org/10.1007/s00484-0110453-2

Bodrud-Doza M, Shammi M, Bahlman L, Islam ARMT, Rahman MM (2020) Psychosocial and socio-economic crisis in Bangladesh due to COVID-19 pandemic: a perception-based assessment. Front Public Health 8:341. https://doi.org/10.3389/fpubh.2020.00341

Bowler K (2005) Acclimation, heat shock and hardening. J Thermal Biology 30(2):125-130. https://doi.org/10.1016/j.jtherbio.2004.09. 001

Brouillet A, Joussaume S (2019) Investigating the role of the relative humidity in the co-occurrence of temperature and heat stress extremes in CMIP5 Projections. Geophys Res Lett 46:11435-11443. https://doi.org/10.1029/2019GL084156

Budd GM (2008) Wet-bulb globe temperature (WBGT) — its history and its limitations. J Sci Med Sport 11(1):20-32

Burkart K, Schneider A, Breitner S, Khan MH, Krämer A, Endlicher W (2011) The effect of atmospheric thermal conditions and urban thermal pollution on all-cause and cardiovascular mortality in Bangladesh. Environ Pollut 159(8-9):2035-2043

Burkart K, Breitner S, Schneider A, Khan MMH, Krämer A, Endlicher W (2014) An analysis of heat effects in different subpopulations of Bangladesh. Int J Biometeorol 58(2):227-237

Buzan JR, Oleson K, Huber M (2015) Implementation and comparison of a suite of heat stress metrics within the Community Land Model version 4.5. Geosci Model Dev 8(2):151-170. https://doi.org/10. 5194/gmd81512015

Chavaillaz Y, Roy P, Partanen AI. et al. (2019) Exposure to excessive heat and impacts on labour productivity linked to cumulative $\mathrm{CO} 2$ emissions. Sci Rep 9:13711. https://doi.org/10.1038/s41598-01950047-w

Das J, Umamahesh NV (2016) Downscaling monsoon rainfall over river Godavari Basin under different climate-change scenarios. Water Resour Manag 30(15):5575-5587

De Freitas CR, Grigorieva EA (2014) A comprehensive catalogue and classification of human thermal climate indices. Int J Biometeorol 2014:1-12

Dinpashoh Y, Mirabbasi R, Jhajharia D, Abianeh HZ, Mostafaeipour A (2014) Effect of short-term and long-term persistence on identification of temporal trends. J Hydrol Eng 19(3):617-625

Dissanayaka KDCR (2017) Climate extremes and precipitation trends in Kelani river basin, Sri Lanka and impact on streamflow variability under climate change, http://dl.lib.mrt.ac.lk/handle/123/14594. Accessed18 Dec 2020

Dixon PG, Brommer DM, Hedquist BC, Kalkstein AJ, Goodrich GB, Walter JC, Cerveny RS (2005) Heat mortality versus cold mortality: a study of conflicting databases in the United States. Bull Am Meteorol Soc 86(7):937-944

Fahad MGR, Saiful Islam A et al (2018) Regional changes of precipitation and Temperature over Bangladesh using bias- corrected multimodel ensemble projections considering high-emission pathways. Int J Climatol 38(4):1634-1648

Field CB, V.R. Barros DJ, Dokken KJ, Mach MD, Mastrandrea TE et al. (2014) Climate Change 2014: Impacts, adaptation, and vulnerability. Part A: Global and sectoral aspects. Contribution of working group II to the fifth assessment report of the intergovernmental panel on climate change. Cambridge University Press, Cambridge, United Kingdom and New York, NY, USA, p. 1132

Fischer EM, Oleson KW, Lawrence DM (2012) Contrasting urban and rural heat stress responses to climate change. Geophys Res Lett 39(3):L03705. https://doi.org/10.1029/2011GL050576

Gagnon S, Singh B, Rousselle J, Roy L (2005) An application of the statistical downscaling model (SDSM) to simulate climatic data for streamflow modelling in Québec. Can Water Resour J 30(4): 297-314. https://doi.org/10.4296/cwrj3004297

Ghose B, Islam ARMT, Kamruzzaman M, Moniruzzaman M, Hu Z (2021) Climate-induced rice yield anomalies linked to large-scale atmospheric circulation in Bangladesh using multi-statistical modeling, Theor Appl Climatol, 144:1077-1099. DOI: https://doi.org/10. 1007/s00704-021-03584-2

Global Change (2018) Impacts, risks, and adaptation in the United States: The Fourth National Climate Assessment, Volume II. U.S. Global Change Research Program1800 G Street, NW, Suite 9100, Washington, DC 20006 USA, https://data.globalchange.gov/ report/nca4. DOI : https://doi.org/10.7930/NCA4.2018, Accessed 10 Jan 2021

Hamed KH, Rao AR (1998) A Modified Mann-Kendall trend test for autocorrelated data. J Hydrol 204:182-196

Hansen J, Sato M, Ruedy R (2012) Perception of climate change. PNAS (Proceeding National of the acedemy Science) 109(37):E2415E2423. https://doi.org/10.1073/pnas.1205276109

Hansen MC, Stehman SV, Potapov PV et al. (2008) Humid tropical forest clearing from 2000 to 2005 quantified by using multitemporal and multiresolution remotely sensed data, PNAS, 105(27):9439-9444. https://doi.org/10.1073/pnas.0804042105

Havenith G, Fiala D (2016) Thermal indices and thermophysiological modeling for heat stress. Compr Physiol 6:255-302

Hondula DM, Balling RC, Vanos JK et al (2015) Rising temperatures, human health, and the role of adaptation. Curr Clim Change Rep 1: 144-154. https://doi.org/10.1007/s40641-015-0016-4

Huq S (2001) Climate change and Bangladesh. Science 294:1617. https:// doi.org/10.1126/science.294.5547.1617

Im ES, Pal JS, Eltahir EA (2017) Deadly heat waves projected in the densely populated agricultural regions of South Asia. Sci Adv 3(8):e1603322

IPCC (2014) Climate change 2014: the physical science basis Contribution of working group I to the fifth assessment report of the intergovernmental panel on climate change [Stocker, T.F., D. Qin, G.-K. Plattner, M. Tignor, S.K. Allen, J. Boschung, A. Nauels, Y. Xia, V. Bex and P.M. Midgley (eds.)]. Cambridge University Press, Cambridge, United Kingdom and New York, NY, USA, p. 1535

IPCC (2019) Global Warming of $1.5^{\circ} \mathrm{C}$. An IPCC Special Report on the impacts of global warming of $1.5^{\circ} \mathrm{C}$ abovepre-industrial levels and related global greenhouse gas emission pathways, in the context of strengthening the globalresponse to the threat of climate change, sustainable development, and efforts to eradicate poverty [MassonDelmotte VP, Zhai HO, Pörtner D, Roberts J, Skea PR, Shukla A, 
Pirani, W. Moufouma-Okia, C. Péan, R. Pidcock, S. Connors,J.B.R. Matthews, Y. Chen, X. Zhou, M.I. Gomis, E. Lonnoy, T. Maycock, M. Tignor, and T. Waterfield (eds.)]. In Press

Islam ARMT, Shen S, Hu Z, Rahman MA (2017) Drought hazard evaluation in boro paddy cultivated areas of western Bangladesh at current and future climate change conditions, Adv. Meteorol. 2017, Article ID 3514381, 12p. https://doi.org/10.1155/2017/3514381

Islam ARMT, Shen S, Yang SB, Hu Z, Chu R (2019) Assessing recent impacts of climate change on design water requirement of Boro rice season in Bangladesh. Theor Appl Climatol 138:97-113. https://doi. org/10.1007/s00704-019-02818-8

Islam ARMT, Ahmed I, Rahman MS (2020) Trends in cooling and heating degree-days overtimes in Bangladesh? An investigation of the possible causes of changes. Natural Hazards 101:879-909. https://doi.org/10.1007/s11069-020-03900-5

Islam ARMT, Islam HMT, Shahid S, Khatun MK, Ali MM, Rahman M, Ibrahim SM, Almoajel AM (2021) Spatiotemporal nexus between vegetation change and extreme climatic indices and their possible causes of change. J Environ Manag 289:112505. https://doi.org/10. 1016/j.jenvman.2021.112505

Javaherian M, Ebrahimi H, Aminnejad B (2021) Prediction of changes in climatic parameters using CanESM2 model based on Rcp scenarios (case study): Lar dam basin. Ain Shams Eng J. 12(1):445-454. https://doi.org/10.1016/j.asej.2020.04.012

Jhajharia D, Chattopadhyay S, Choudhary RR, Dev V, Singh VP, Lal S (2013) Influence of climate on incidences of malaria in the Thar Desert, northwest India. Int J Climatol 33(2):312-325

Jhajharia D, Dinpashoh Y, Kahya E, Choudhary RR, Singh VP (2014) Trends in temperature over Godavari river basin in southern peninsular India. Int J Climatol 34(5):1369-1384

Kendall M (1955) Rank Correlation Methods. 1st ed. Charles Griffin and Co. Ltd. London, UK

Kendall MG (1975) Rank Correlation Methods. 4th ed. Charles Griffin and Co. Ltd: London, UK

Khadka D, Pathak D (2016) Climate change projection for the marsyangdi river basin, Nepal using statistical downscaling of GCM and its implications in geodisasters. GeoEnv. Disaster 3(1): $1-15$

Khan MHR, Rahman A, Luo C, Kumar S, Islam GMA, Hossain MA (2019) Detection of changes and trends in climatic variables in Bangladesh during 1988-2017. Heliyon. 5(3):e01268

Kirtman B, Coauthors (2013) Near-termClimate change: projections and predictability. In: Climate change 2013: the physical science basis. Contributionof working group I to the fifth assessment report of the intergovernmental panel on climate change [Stocker,T.F., D. Qin, G.-K. Plattner, M. Tignor, S.K. Allen, J. Boschung, A. Nauels, Y. Xia, V. Bex and P.M. Midgley (eds.)].Cambridge University Press, Cambridge, United Kingdom and New York, NY, USA

Kjellstrom T, Holmer I, Lemke B (2009) Workplace heat stress, health and productivity - an increasing challenge for low and middleincome countries during climate change. Glob Health Action 2(1): 2047. https://doi.org/10.3402/gha.v2i0.2047

Kjellstrom T, Briggs D, Freyberg C, Lemke B, Otto M, Hyatt O (2016) Heat, human performance, and occupational health: a key issue for the assessment of global climate change impacts. Annu Rev Public Health 37:97-112. https://doi.org/10.1146/annurev-publhealth032315-021740

Li J, Chen YD, Gan TY, Lau NC (2018) Elevated increases in humanperceived temperature under climate warming. Nat Clim Chang 8(1):43-47. https://doi.org/10.1038/s4155801700362

Mann HB (1945) Nonparametric tests against trend. Econometrica 13: 245-259

McGregor H, Evans M, Goosse H et al (2015) Robust global ocean cooling trend for the pre-industrial Common Era. Nat Geosci 8: 671-677. https://doi.org/10.1038/ngeo2510
Modarres R, Ghadami M, Naderi S, Naderi M (2018) Future heat stress arising from climate change on Iran's population health. Int $\mathrm{J}$ Biometeorol 62:1275-1281. https://doi.org/10.1007/s00484-018$1532-4$

Monteiro A, Carvalho V, Oliveira T, Sousa C (2013) Excess mortality and morbidity during the July 2006 heat wave in Porto, Portugal. Int J Biometeorol 57:155-167. https://doi.org/10.1007/s00484-0120543-9

Mora C, Dousset B, Caldwell IR, Powell FE, Geronimo RC, Bielecki CR, Counsell CWW, Dietrich BS, Johnston ET, Louis LV, Lucas MP, McKenzie MM, Shea AG, Tseng H, Giambelluca TW, Leon LR, Hawkins E, Trauernicht C (2017) Global risk of deadly heat. Nat Clim Chang 7(7):501-506. https://doi.org/10.1038/nclimate3322

Nguyen JL, Dockery DW (2016) Daily indoor-to-outdoor Temperature and humidity relationships: a sample across seasons and diverse climatic regions. Int J Biometeorol 60:221-229. https://doi.org/10. 1007/s00484-015-1019-5

Nissan H, Burkart K, De perez EC, Van Aalst M, Mason S (2017) Defining and Predicting Heat Waves in Bangladesh. J Appl Meteorol Climatol 56(10):2653-2670. https://doi.org/10.1175/ JAMC-D-17-0035.1

Nissan H, Muñoz AG, Mason SJ (2020) Targeted model evaluations for climate services: a case study on heat waves in Bangladesh. Cliamte Risk Manage 28:100213

Pal JS, Eltahir EAB (2016) Future Temperature in southwest Asia projected to exceed a threshold for human adaptability. Nat Clim Chang 6:197-200

Praveen B, Talukdar S, Shahfahad MS, Mondal J, Sharma P, Islam ARMT, Rahman A (2020) Analyzing trend and forecasting of rain- fall changes in India using non-parametrical and machine learning approaches. Sci Rep 10:10342. https://doi.org/10.1038/ s41598-020-67228-7

Rahman MS, Islam ARMT (2019) Are precipitation concentration and intensity changing in Bangladesh overtimes? Analysis of the possible causes of changes in precipitation systems. Sci Total Environ 690:370-387. https://doi.org/10.1016/j.scitotenv.2019.06.529

Rahman MA, Yunsheng L, Sultana N (2017) Analysis and prediction of rainfall trends over Bangladesh using Mann-Kendall, Spearman's rho tests and ARIMA model. Meteorog Atmos Phys 129(4):409_ 424

Rahman MM, Ahmad S, Mahmud AS, Hassan-uz-Zaman M, Nahian MA, Ahmed A, Nahar Q, Streatfield PK (2019) Health consequences of climate change in Bangladesh: an overview of the evidence, knowledge gaps and challenges. WIREs Clim Change 10: e601. https://doi.org/10.1002/wcc.601

Rajib MA, Mortuza R, Selmi S, Ankur AK (2011) Increase of heat index over Bangladesh: Impact of climate change, Bangladesh, World Academy of Science, Engineering and Technology, 5(10):402-405

Rakib Z (2013) Extreme Temperature Climatology and Evaluation of Heat Index in Bangladesh. Presidency University 2(2):84-95

Rakib Z (2018) Characterization of climate change in southwestern Bangladesh: trend analyses of temperature, humidity, heat index, and rainfall. Clim Res 76(3):241-252

Raymond C, Singh D, Horton RM (2017) Spatiotemporal patterns and synoptics of extreme wet-bulb temperature in the contiguous United States. J Geophys Res Atmos 122(24):13-108

Saddique N, Bernhofer C, Kronenberg R, Usman M (2019) Downscaling of CMIP5 models output by using statistical models in a data scarce mountain environment (Mangla Dam Watershed), Northern Pakistan. Asia-Pac J Atmos Sci 55(4):719-735

Salam R, Islam ARMT (2020) Potential of RT, Bagging and RS ensemble learning algorithms for reference evapotranspiration prediction using climatic data-limited humid region in Bangladesh. J Hydrol 590:125241. https://doi.org/10.1016/j.jhydrol.2020.125241

Salam R, Islam ARMT, Pham QB, Dehghani M, Al Ansari N, Linh NTT (2020) The optimal alternative for quantifying reference 
evapotranspiration in climatic sub-regions of Bangladesh. Sci Rep 10(1):20171. https://doi.org/10.1038/s41598-020-77183-y

Sen PK (1968) Estimates of the regression coefficient based on Kendall's tau. J Am Stat Assoc 63(324):1379-1389

Shafiq MU, Ramzan S, Ahmed P. et al. (2019) Assessment of present and future climate change over Kashmir Himalayas, India. Theor Appl Climatol 137:3183-3195. https://doi.org/10.1007/s00704-01902807-x

Shammi M, Bodrud-Doza M, Islam ARMT, Rahman MM (2020) COVID-19 pandemic,socioeconomic crisis and human stress in resource-limited settings: a case from Bangladesh. Heliyon 6: e04063. https://doi.org/10.1016/j.heliyon.2020.e04063

Singh M, Rao M, Butler CD (2016) Climate change, health and future well-being in South Asia. In Advances in Asian HumanEnvironmental Research (pp. 11-27). (Advances in Asian HumanEnvironmental Research; No. 9783319236834). Springer. https:// doi.org/10.1007/978-3-319-23684-1 2

UN ESCAP (2015) The UN Economic and Social Commission for Asia and the Pacific. Disasters in Asia and the Pacific: 2015 Year in Review https://www.unescap.org/resources/disasters-asia-andpacific-2015-year-review. Accessed 10 Dec 2020

UNISDR (2018) The United Nations Office for Disaster Risk Reduction, annual report 2018, p. 107. https://www.undrr.org/publication/ united-nations-office-disaster-risk-reduction-2018-annual-report, Accessed 20 Jan 2021
Vousoughi FD, Dinpashoh Y, Aalami MT, Jhajharia D (2013) Trend analysis of groundwater using nonparametric methods (case study: Ardabil plain). Stoch Env Res Risk A 27(2):547-559

Wang F, Zhang J (2019) Heat Stress Response to National-Committed Emission Reductions under the Paris Agreement. Int J Environ Res Public Health 16(12):2202. https://doi.org/10.3390/ijerph16122202

Wilby RL, Dawson CW (2007) Statistical downscaling model (SDSM), version 4.2. Department of Geography, Lancaster University, Lancashire, p. 94

Yengoh GT, Ardö J (2020) Climate change and the future heat stress challenges among smallholder farmers in East Africa. Atmosphere 11:753. https://doi.org/10.3390/atmos11070753

Yue S, Wang C (2004) The Mann-Kendall test modified by effective sample size to detect trend in serially correlated hydrological series. Water Resour Manag 18(3):201-218

Zamani R, Mirabbasi R, Abdollahi S, Jhajharia D (2017) Streamflow trend analysis by considering autocorrelation structure, long-term persistence, and Hurst coefficient in a semi-arid region of Iran. Theor Appl Climatol 129(1):33-45

Zinat MRM, Salam R, Badhan MA, Islam ARMT (2020) Appraising drought hazard during Boro rice growing period in western Bangladesh. Int J Biometeorol 64:1687-1697. https://doi.org/10. 1007/s00484-020-01949-2

Publisher's note Springer Nature remains neutral with regard to jurisdictional claims in published maps and institutional affiliations. 